\title{
CARACTERÍSTICAS DO AVALIADOR E DAS COMISSÕES DE AVALIAÇÃO COMO FATORES DETERMINANTES NA ANÁLISE DIDÁTICO-PEDAGÓGICA DE CURSOS ${ }^{1}$
}

\author{
Paulo Cesar Chanan-Silva ${ }^{2}$ \\ Centro Universitário Maurício de Nassau de Recife \\ paulo.chanan@sereducacional.com
}

Luciana Rodrigues Ferreira ${ }^{3}$ Universidade da Amazônia - UNAMA luciana.ferreira@unama.br

\begin{abstract}
Resumo
No presente trabalho analisa a influência das características de avaliadores e Comissões de Avaliação sobre o conceito obtido na dimensão didático-pedagógica, constante do instrumento de avaliação utilizado pelo INEP/MEC, para avaliar a qualidade de cursos de graduação no Brasil. A metodologia se desenha como estudo exploratório de abordagem qualitativa, utilizando-se os seguintes procedimentos metodológicos: a) revisão bibliográfica; e b) mapeamento de dados com análise estatística, sob as variáveis: a formação de graduação dos avaliadores, a titulação máxima dos avaliadores, o modelo de gestão das Instituições de origem dos avaliadores e a origem geográfica dos Avaliadores e, como variável resposta, o conceito atribuído pelas Comissões às avaliações realizadas, sob condições controladas, de cursos de administração. Após análise estatística direta dos resultados observou-se uma relação entre as características dos avaliadores/Comissões de Avaliação e os conceitos emitidos, não sendo possível, inferir se tais avaliações (dentro das condições averiguadas) são capazes de induzir a qualidade nos cursos avaliados, objetivo primordial dos processos avaliativos desenvolvidos pelo INEP/MEC.
\end{abstract}

Palavras-chave: Politica Educacional; Gestão Institucional; Avaliação de Cursos; Avaliador.

\section{CHARACTERISTICS OF THE EVALUATORS AND EVALUATION COMMITTEES AS DETERMINING FACTORS IN DIDACTIC-PEDAGOGICAL ANALYSIS}

\begin{abstract}
This paper analyzes the influence of the characteristics of evaluators and Evaluation Committees on the concept obtained in the didactic-pedagogical dimension of analysis, included in the evaluation instrument used by INEP / MEC, to evaluate the quality of undergraduate courses in Brazil. The methodology is designed as an exploratory study of a qualitative approach, using the following methodological procedures: a) bibliographic review; and b) data mapping with statistical analysis, under the variables: the graduation training of the evaluators, the maximum degree of the evaluators, the management model of the institutions of origin of the evaluators and the geographical origin of the Evaluators and, as a response variable, the concept attributed by the Commissions to the evaluations carried out, under controlled conditions, in Administration courses. After a direct statistical analysis of the results, there was a relationship between the characteristics of the evaluators / Evaluation Committees and the concepts emitted, and it is not possible to infer if such evaluations (within the conditions verified) are capable of inducing quality in the evaluated courses, objective of the evaluation processes developed by INEP/MEC.
\end{abstract}

Keywords: Educational politics. Institutional Management. Course Evaluation. Evaluator.

\footnotetext{
${ }^{1}$ A primeira versão deste artigo foi apresentada no IX Colóquio Organizações, Desenvolvimento e Sustentabilidade.

${ }^{2}$ Mestrando em Administração pela Universidade da Amazônia (UNAMA), Diretor de regulação do Grupo Ser Educacional. Centro Universitário Maurício de Nassau de Recife.

${ }^{3}$ Pós-doutorado no campo da Política de financiamento da Pós-Graduação, Pesquisa \& Desenvolvimento no Brasil. Doutora em Educação, linha de Estado, Política e Formação Humana, pela Universidade Federal de São Carlos (UFSCar). Professora do Programa de Pós-Graduação em Administração na Universidade da Amazônia (PPAD/UNAMA) e coordenadora do Centro de Estudos, Pesquisas e Projetos Estratégicos em Governança Pública (CEPPE/EGPA).
}

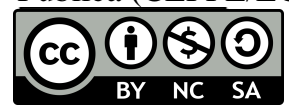

P2P \& INOVAÇÃO, Rio de Janeiro, v. 5 n. 1, p.102-119, Set./Fev. 2018. 


\section{INTRODUÇÃO}

Embora o Brasil seja um País de mais de 500 anos, a educação superior, de fato, só começou a existir a partir da vinda da Família Real Portuguesa. O ano de 1808 marca a constituição das duas primeira Faculdades brasileiras, a Faculdade de Cirurgia da Bahia, em Salvador e a Faculdade de Medicina do Rio de Janeiro. Até 1983 não havia nenhum sistema de avaliação do ensino superior no Brasil, foi quando surgiu o primeiro Programa de Avaliação submetido a discussão no extinto Conselho Federal de Educação e aprovado pelo Ministério da Educação (MEC), o Programa de Avaliação da Reforma Universitária (PARU).

A abrangência do PARU era apenas às Universidades Públicas e o Programa apenas recolheu dados. Não durou nem um ano e mesmo antes dos dados serem analisados o Programa foi desativado. Em 1988, a nova Constituição Federal brasileira trouxe em seu art. 209, inciso II, o assunto da avaliação do ensino, em todas as modalidades, à baila novamente.

Apresenta-se nos anos de 1993, o Programa de Avaliação Institucional das Universidades Brasileiras (PAIUB), instituído em 1993 pelo Ministério da Educação (MEC) para que as universidades criassem sistemas internos de avaliação - com posterior checagem pelos técnicos do MEC, afim de auxiliar no processo de aperfeiçoamento da instituição.

Na sequencia, têm-se 1995 a Lei n. 9.1311 que implementa o Exame Nacional de Cursos (ENC), popularmente conhecido como o Provão, a ser aplicado a todos os estudantes concluintes de campos de conhecimento pré-definidos. Legislações subseqüentes incluíram no sistema o Censo de Educação Superior e a Avaliação das Condições de Ensino (ACE), realizadas por meio de visitas de comissões externas às Instituições de Ensino Superior (IES).

Somente em 2004, com o advento da Lei n.10.861, constitui-se no Brasil o Sistema Nacional de Avaliação do Ensino Superior (SINAES), sob a regulação e supervisão do MEC, com o "[...] objetivo de assegurar o processo nacional de avaliação das instituições de educação superior, dos cursos de graduação e do desempenho acadêmico de seus estudantes" (BRASIL, 2004, p. 12). Sistema que marca o início avaliações periódicas e sistêmicas em todas as instituições de ensino superior e de cursos de graduação no país.

Na política do SINAES, que prevalece até os dias atuais, está previsto que, para o funcionamento regular, a IES deve passar por um processo de credenciamento institucional, que engloba uma avaliação da qualidade da futura instituição e suas políticas e por processos avaliativos de autorização em todos os cursos de graduação que pretende oferecer. Após o credenciamento e autorização dos cursos, a IES passará por avaliações cíclicas e periódicas, tanto institucionais, quanto nos cursos. As institucionais são os recredenciamentos, que visam 
verificar periodicamente o cumprimento do Plano de Desenvolvimento Institucional (PDI) da IES e suas Políticas Institucionais e, as de curso, os reconhecimentos e renovações de reconhecimentos, que objetivam aferir o cumprimento dos Projetos Pedagógicos dos Cursos e toda normatização institucional a eles ligada.

Desta forma, diferentemente de outros países nos quais a criação de IES e oferta de cursos são antecedidos apenas de etapas administrativas, no Brasil temos um ambiente inteiramente regulado pelo Estado, sendo necessárias diversas etapas e avaliações para que as IES se mantenham em funcionamento e para que seus cursos de graduação possam ter oferta regular.

As avaliações da Educação Superior no Brasil ocorrem sob a responsabilidade do Instituto Nacional de Estudos e Pesquisas Educacionais Anísio Teixeira (INEP) (BRASIL, 1937, 2001), uma autarquia vinculada ao Ministério da Educação e estão regulamentadas por decretos e leis que regem as avaliações e os instrumentos utilizados nestas (BRASIL, 2001, 2006; BRASIL, 2016).

As avaliações in loco em cursos de graduação são realizadas por avaliadores cadastrados no Banco de Avaliadores do Sistema Nacional de Avaliação da Educação Superior (BASIS) (BRASIL, 2004), os quais são treinados pelo próprio INEP, estando desta forma aptos para realização de avaliações de forma padronizada e objetiva, sob um Instrumentos de Avaliação. Trata-se de uma espécie de roteiro de auditoria que, no caso dos cursos, denomina-se Instrumento de Avaliação de Cursos de Graduação - IACG (INEP, 2015) e são utilizados pelos avaliadores com o intuito de verificar, in loco, indicadores de qualidade dos cursos; qualidade esta que é mensurada a partir de quatro seções (denominadas dimensões): Dimensão Didáticopedagógica; Dimensão Corpo Docente e Tutorial; Dimensão Infraestrutura; e Requisitos Legais. A média ponderada dos conceitos finais das Dimensões 1, 2 e 3 gera o Conceito Global Final da avaliação.

Mesmo sendo as avaliações de cursos direcionadas pelo IACG (INEP, 2015) (que exige dos auditores posição direta e imparcial, segundo a norma) com indicadores fixos e objetivos; mesmo tendo sido os avaliadores treinados a partir do mesmo eixo formativo pelo INEP; questiona-se: em que medida a variação de subjetividade no processo de avaliação dos cursos de graduação interfere no resultado final das avaliações?

Desse modo, o presente artigo, tem por objetivo verificar o grau de subjetividade dos avaliadores externos de curso, com intuito de analisar os resultados ao final das avaliações.

O texto está organizado em quatro seções: esta introdução, a segunda que trata sobre os referenciais teóricos, na terceira seção aborda-se os procedimentos regulatórios do SINAES, a 
quarta seção identifica-se sobre a metodologia e os procedimentos de pesquisa, e na quinta, expõe-se os resultados.

\section{REFERENCIAL TEÓRICO}

A presente seção apresentará as noções básicas dos conceitos aplicados para se chegar a solução proposta no artigo in foco: a) A politica educacional no Ensino Superior - aportes internacionais sobre o Estado; e b) Auditoria como base estratégica de Qualidade.

\subsection{A POLÍTICA EDUCACIONAL NO ENSINO SUPERIOR - APORTES INTERNACIONAIS SOBRE O ESTADO}

O processo de reformulação do capital que redimensionou a organização do Estado e de sua administração em novas relações entre o Estado e Sociedade, pela lógica neoliberal, principalmente em países em desenvolvimento, nos anos de 1990, que incentivados por organismos multilaterais, como o Fundo Monetário Internacional (FMI) e o Banco Mundial $(\mathrm{BM})$, orientaram na lógica internacional de desenvolvimento do capital e das formas de governo, sobre a qual a formatação dos sistemas de ensino se consolidaram.

No Brasil, as mudanças se deram especialmente a partir do governo de Fernando Henrique Cardoso (1995-2002), tendo como marco a Reforma do Estado em 1995, com a criação do Ministério da Administração Federal e Reforma do Estado (MARE), sob orientação do então Ministro Luiz Carlos Bresser Pereira, principal mentor da reforma. Baseada na perspectiva gerencial dos organismos internacionais a reforma do Estado reestruturou os serviços públicos sociais, como educação, cultura e saúde.

Para Bresser Pereira, a América Latina, a partir de 1980, entrou em uma dura crise fiscal, acentuada pela dívida externa dos países. Diante disso, seria necessária uma reforma administrativa que garantisse a disciplina fiscal, a privatização e a liberação comercial, nas quais o Estado mantém a responsabilidade social e, em contrapartida, incentiva e incrementa os serviços via mercado (BRESSER PEREIRA, 2007, p. 23).

Dentre as publicações do ex-ministro Bresser Pereira para o MARE, destaca-se "A reforma do Estado dos anos 1990: lógica e mecanismos de controle", na qual a Reforma é entendida como:

Um processo de criação ou de transformação de instituições, de forma a aumentar a governança e a governabilidade. Privatização é um processo de transformar uma empresa estatal em privada. Publicização, de transformar uma organização estatal em uma organização de direito privado, mas pública não-estatal. Terceirização é o 
processo de transferir para o setor privado serviços auxiliares ou de apoio. No seio do Estado estrito senso, onde se realizam as atividades exclusivas de Estado, a clara distinção entre secretarias formuladoras de políticas públicas, agências executivas e agências reguladoras autônomas implica em criação ou redefinição das instituições. (BRESSER PEREIRA, 1997, p. 19, grifo nosso).

Objetivos estes, constituídos pelo MARE, por meio de um Plano Diretor da Reforma do Estado (PDRE), documento que materializa as ações desejadas para o 'enquadramento' do Brasil nesse novo modelo. Para Fernando Henrique Cardoso, a reforma do Estado não está ligada à mudança de identidade, mas "significa, antes de tudo, abandonar visões do passado de um Estado assistencialista e paternalista”, observando que esta mudança é necessária para o Estado se adaptar às novas exigências mundiais, um processo que levará, segundo ele, o Estado a enfrentar gigantescos desafios no mundo globalizado (CARDOSO, 2006, p. 15).

De forma geral, a Reforma do Estado influenciou diretamente na reestruturação da educação pública e privada no Brasil, especialmente a educação superior, seja a publica pela visão que fomenta, gradativamente, nas universidades a necessidade de estabelecer parcerias com entidades privadas, ou em IES privadas que passam a adequar-se aos novos critérios de credenciamento e avaliação de cursos, com vistas a maior capacidade de atender a população e estar apta a resguardar o fundo publico aplicado para reserva de vagas. (AMARAL, 2003, p. $54)$.

Embora este processo de ajustamento a uma nova lógica de reorganização tenha sido, e ainda o é, complexo e dinâmico, seja pelo consentimento gradual e efetivo de políticas de gestão da educação superior por meio da efetivação de regulação nacional e parcerias Inter setoriais, cujo o foco no período de reforma gerencial se organiza em processos avaliativos sistematizados, com expoente na metade da década de 1990, quando o governo brasileiro inicia um processo gradual de implementação de um sistema de avaliação do ensino superior, que culmina, em 2004, com a implementação do Sistema Nacional de Avaliação da Educação Superior (SINAES), instituído pela Lei Federal nº 10.861.

\subsection{AUDITORIA COMO BASE PARA A BUSCA DA MELHORIA CONTÍNUA}

Como o objetivo de todo empreendimento passa por melhoria de processos para obtenção de melhores resultados, a auditoria entra como forte aliada, caracterizando-se como uma verificação sistemática, na qual se observa se as atividades desenvolvidas pela organização estão de acordo com critérios e padrões previamente estabelecidos, fornecendo dados que podem promover a aferição e melhoria do que está sendo desenvolvido (AUDIBRA, 1991; PINHO, 2007). 
Toda auditoria passa por, pelo menos, três fases bem definidas, são elas: a) planejamento e programa; b) execução; e d) resultado final.

No planejamento, fase mais importante de qualquer auditoria, determina-se o objetivo e o alcance do trabalho, levando-se em conta as características da auditoria e as especificidades do local e do objeto que será auditado (FRANCO, MARRA, 1992).

Por seu turno, o programa, configura-se num plano de ação a ser executado, com a finalidade de alcançar os objetivos da auditoria (CREPALDI, 2000).

$\mathrm{Na}$ execução, checa-se a situação real de funcionamento do que está sendo auditado, com o cuidado de que toda atividade programada seja desenvolvida em formulário próprio, previamente desenhados, que precisam ser completos e detalhados, para que o auditor possa compreender plenamente o trabalho a ser realizado (ALMEIDA, 1990).

Por último, na apresentação do resultado final, faz-se uma análise de confronto entre o que foi executado e o que foi planejado. Os relatórios produzidos servirão para a construção de um novo planejamento, ou planos de ações para correção de curso, no caso de ainda haver prazo, para execução do planejado.

A auditoria sistemática (cíclica e periódica) tem como ponto final possibilitar a melhoria contínua do que está sendo avaliado, num processo de correção permanente de curso, evitando anomalias procedimentais, o que permite a inovação e introdução de inéditos mecanismos capazes de gerar, com mais acuracidade, o resultado planejado (COSTA, 2006).

É nesse processo de auditoria, que têm sido conduzidas as avaliações de cursos de graduação do ensino superior no Brasil, em atendimento a Lei do SINAES (BRASIL, 2004), com utilização obrigatória do IACG (BRASIL, 2004).

\section{A AVALIAÇÃO DA EDUCAÇÃO SUPERIOR COMO INDUTOR DE QUALIDADE DE CURSOS DE GRADUAÇÃO}

O eixo de destaque neste trabalho é sobre a avaliação externa e a mensuração de qualidade postas em seus instrumentos, "essa avaliação é feita por membros externos, pertencentes à comunidade acadêmica e científica, reconhecidos pelas suas capacidades em áreas específicas e portadores de ampla compreensão sobre instituições universitárias" (MEC, 2018).

Vale destacar que no processo de autorização de funcionamento de uma IES privada, por exemplo, a mantenedora (empresa) de educação superior, nos moldes constitucionais e legais brasileiros, mantém uma ou várias IES (mantida(s)) (BRASIL, 1996). Para o 
funcionamento, nesta(s) são autorizados e desenvolvidos cursos de graduação, que necessitam atender a uma regulação normativa diferenciada e específica, que é toda fundamentada na necessidade de se prestar o serviço educacional nesses ditos cursos, dentro de padrões de qualidade previamente estabelecidos pelos indicadores do IACG (INEP, 2015) e pelas Diretrizes Curriculares Nacionais do Curso, caso haja. Tais padrões, atualmente, insurgem, de forma primária, na Lei do SINAES (BRASIL, 2004), que amplia e referenda a LDB - Lei de Diretrizes e Bases da Educação Brasileira (BRASIL, 1996).

A Lei do SINAES (BRASIL, 2004) sedimenta-se na avaliação como mensuradora e indutora da qualidade esperada para os cursos de graduação de ensino superior, razão pela qual delimita e norteia todo o processo avaliativo a ser desenvolvido pelo INEP (BRASIL, 1937; BRASIL, 2001).

\subsection{OS MOMENTOS DE AVALIAÇÃO NOS CURSOS DE GRADUAÇÃO}

A Lei dos SINAES (BRASIL, 2004) criou a CONAES - Comissão Nacional de Avaliação da Educação Superior, órgão colegiado vinculado ao Gabinete do Ministro de Estado da Educação e deu a ela, dentre outras, a atribuição de elaborar o Instrumento de Avaliação de Cursos de Graduação - IACG (INEP, 2015), que serve de base para toda e qualquer avaliação de curso de graduação a ser feita em qualquer parte do território brasileiro.

O IACG, por sua vez, delimita o processo avaliativo, dividindo-o em 4 (quatro) grandes dimensões, como esmiuçado na Introdução acima, a primeira, avalia a organização didáticopedagógica, a segunda, analisa o corpo docente, a terceira, avalia as instalações físicas (infraestrutura), e, a quarta, avalia os requisitos legais obrigatórios, a saber:

1) Dimensão Didático-pedagógica: pretende observar a qualidade acadêmicopedagógica dos cursos e suas atividades, em consonância com o egresso pretendido pelo curso. Essa Dimensão, no IACG, é composta por 27 (vinte e sete) indicadores. A média dos conceitos aplicados na Dimensão 1 gera o Conceito Final da Dimensão 1;

2) Dimensão Corpo Docente e Tutorial: pretende mensurar a qualidade dos recursos humanos, docentes e tutores, alocados para o desenvolvimento do curso. Essa Dimensão, no IACG, é composta por 20 (vinte) indicadores. A média dos conceitos aplicados na Dimensão 2 gera o Conceito Final da Dimensão 2;

3) Dimensão Infraestrutura: almeja mensurar a qualidade dos recursos físicos (salas de aula, laboratórios, biblioteca, etc) e tecnológicos (equipamentos em geral, equipamentos de informática, etc) disponíveis para o curso. Essa Dimensão, no IACG, é composta por 22 (vinte e dois) indicadores. A média dos conceitos aplicados na Dimensão 3 gera o Conceito Final da Dimensão 3;

4) Requisitos Legais: busca aferir itens específicos e pontuais impostos pela legislação vigente. No IACG atual, essa dimensão é composta por 17 (dezessete) indicadores, que não são aferidos com conceitos numéricos, mas sim com as alcunhas de "Atende" ou "Não Atende". (INEP, 2018, s/p). 
A média ponderada dos conceitos finais das Dimensões 1, 2 e 3 gera o Conceito Global Final da avaliação. Todo o processo avaliativo de cursos de graduação no Brasil, por força também da Lei do SINAES (BRASIL, 2004), está sob o comando do INEP (BRASIL, 1937; BRASIL, 2001), que precisa zelar pela regularidade e desenvolvimento das atividades de auditoria dos avaliadores designados junto às instituições e seus cursos de graduação.

As avaliações de cursos de graduação acontecem em três momentos, o primeiro, quando de sua autorização de funcionamento, o segundo, quando do seu reconhecimento e o terceiro, de maneira sistemática (cíclica e periódica), quando de sua renovação de reconhecimento.

Assim, separando-se as etapas temos: a autorização, que visa aferir se as condições que a IES propõe para a oferta inicial do curso atendem aos referenciais de qualidade propostos pela DCN do curso em exame, se houver e pelos referências de qualidade trazidos pelos SIANES e explicitados pelo IACG; o reconhecimento, etapa em que a avaliação verificará o cumprimento ou não da proposta inicial feita para a oferta do curso e, por fim, a renovação de reconhecimento, enquanto o curso estiver ativo, onde será avaliada a manutenção dos padrões de qualidade na oferta do curso.

\subsection{O BANCO DE AVALIADORES DO SINAES}

Como todo processo de auditoria, na avaliação de cursos, faz-se necessário capacitar pessoas para sua condução. Nesse sentido, foi criado, pelo Decreto 5773/2006 (BRASIL, 2006), o Banco de Avaliadores do SINAES (BASIs) -, mantido pelo INEP, o qual conglomera docentes devidamente selecionados e treinados para aplicação do IACG (INEP, 2015). Nos termos da Portaria do INEP n ${ }^{\circ}$ 1.027, de 15 de maio de 2006, somente avaliadores pertencentes ao BASIs estariam aptos a fazerem avaliações in loco nos cursos de graduação do ensino superior das IES brasileiras e, para tanto deveriam possuir titulação mínima de doutor (BRASIL, 2006), exceção faz-se em razão das características próprias dos cursos avaliados, e desde que comprovado o notório saber e a reconhecida qualificação para atuar como avaliador.

O INEP promove periodicamente treinamento e capacitação para os componentes do BASIs (BRASIL, 2006), com vistas a alinhar o entendimento dos avaliadores sobre a aplicação dos indicadores constantes no IACG (INEP, 2015) (de modo similar a preparação de auditores) e, na totalidade das vezes, são encaminhados para as avaliações de cursos 2 (dois) avaliadores sorteados pelo próprio INEP. O fruto desse trabalho é um relatório de avaliação, que baliza o desenvolvimento e continuidade ou não da oferta dos cursos. 


\subsection{OS EFEITOS DO RESULTADO FINAL DA AVALIAÇÃO}

O relatório final da avaliação traz, para cada uma das dimensões, composta por indicadores, um conceito final que varia, segundo a verificação qualitativa desses indicadores da dimensão, de 1 a 5, sendo 1, quando não existente, 2, quando insuficiente, 3, quando suficiente, 4, quando muito bom/muito bem e 5, quando excelente. No que concerne a verificação dos requisitos legais, não há um conceito final para a dimensão, trazendo o relatório final, como resultado, para cada indicador, o "Atende" ou o "Não Atende", deixando claro que não importa a qualidade de atendimento e sim a verificação da obrigatoriedade do atendimento. A média ponderada dos conceitos aplicados às dimensões 1,2 e 3 gera o conceito global final do processo avaliativo

Os padrões decisórios (MEC, 2014.1, 2014.2, 2017) exigem, para que o processo avaliativo seja considerado satisfatório, ao menos conceito global final 3, além do conceito final 3, em cada uma das dimensões e atendimento integral dos indicadores da dimensão dos requisitos legais.

A avaliação que não alcançar tais conceitos sujeita o curso avaliado a processo de supervisão que, inicialmente, passa por uma fase de saneamento das deficiências, impondo algumas restrições a continuidade do curso e, caso numa nova avaliação dentro desse processo de supervisão o curso continue não alcançando os conceitos esperados pelos padrões de qualidade, as sanções são mais severas podendo, inclusive, determinar a cassação da autorização do curso.

\section{METODOLOGIA}

Segundo Chizzotti (1991, p. 79), a abordagem qualitativa parte do pressuposto "de uma relação dinâmica entre o mundo real e o sujeito, uma interdependência viva entre o sujeito e o objeto, um vínculo indissociável entre o mundo do objetivo e a subjetividade do sujeito". Por isso, a opção pela pesquisa qualitativa, por possibilitar análise ampliada sobre o tema, de forma exploratória, pretende-se chegar a análise do objeto de estudo com os procedimentos de revisão de literatura (ALMEIDA, 1990; PINHO, 2007); e pesquisa de campo, com organização e analise de banco de dados. 


\subsection{BANCO DE DADOS}

Para construção do banco de dados, foi desenvolvido um sistema web próprio (denominado Regulação), de um Grupo Educacional nacional, de acesso restrito, executado em servidor específico e com acesso via internet (por login e senha) e acessível através endereço eletrônico, dotado de sistema de criptografia para a segurança.

Embora o acesso seja institucional a criação do Banco de dados ficou a cargo do pesquisador, que se utilizou do Personal Home Page Tools (PHP) como linguagem de programação, sendo que a aplicação web emprega, ainda, como linguagem interpretada pelo navegador, o HTML, XHTML ou XML, e como protocolo de transmissão de dados o HTTP ou HTTPS.

O banco de dados aplicado e acoplado ao sistema é o MYSQL, o qual possui grande suporte à linguagem de programação PHP. Vale ressaltar que o sistema contém 1.182 (um mil, cento e oitenta e dois) relatórios de avaliações de cursos de graduação realizadas no período de 2012 a 2017, com as características abaixo descritas e que contempla:

a) Avaliações de 73 (setenta e três) cursos distintos, de todas as áreas do conhecimento;

b) Avaliações de Cursos de todas as modalidades de graduação: bacharelados, licenciaturas e tecnológicos;

c) Avaliações ocorridas em todos os 26 (vinte e seis) estados do Brasil, e no Distrito Federal;

d) Avaliações de todos os atos regulatórios de cursos: autorização, reconhecimento e renovação de Reconhecimento;

e) Avaliações realizadas em todas as organizações acadêmicas: Faculdades, Centros Universitários e Universidades;

f) Avaliações que contemplam heterogeneidade de características dos avaliadores (unidade federativa de origem, formação, titulação, região de localização da instituição de origem e organização administrativa da instituição de origem);

\subsection{AMOSTRA}

Para o desenvolvimento do presente estudo foram selecionados do Regulação uma amostra composta de 96 (noventa e seis) avaliações do curso de Administração, presencial, bacharelado, com mesmos componentes estruturais do Projeto Pedagógico do Curso apresentados às avaliações. As 96 (noventa e seis) avaliações foram efetuadas em instituições privadas do Brasil, sendo que 7 (sete) delas em Centros Universitários, 4 (quatro) em Universidades e 85 (oitenta e cinco) em faculdades. 
A amostra selecionada reproduz e contempla características baseadas no Universo descrito pela totalidade do Banco de Dados, como pode-se verificar a seguir:

a) Avaliações ocorridas em todas as 27 (vinte e sete) unidades federativas;

b) Avaliações de todos os atos regulatórios: autorização, reconhecimento e renovação de reconhecimento;

c) -Avaliações feitas em todos os tipos de organização acadêmica: Faculdades, Centros Universitários e Universidades

d) Heterogeneidade de características do avaliador (unidade federativa de origem, formação, titulação, região de localização da instituição de origem e organização administrativa da instituição de origem).

\subsection{VARIÁVEIS E CODIFICAÇÃO}

No presente trabalho considerou-se como variáveis que influenciam no processo de avaliação in loco e, consequentemente, interferem na capacidade destas de inferirem qualidade aos cursos, os seguintes fatores:

1) Formação de graduação dos avaliadores (FG);

2) Titulação máxima dos avaliadores (TM);

3) Modelo de gestão das Instituições de origem dos avaliadores (MG);

4) Origem geográfica dos Avaliadores (OG).

Nesse sentido, organizou-se variáveis que foram codificadas conforme Quadro 1, a seguir:

Quadro 1 - Codificação de variáveis, por níveis avaliados, 2018.

\begin{tabular}{|c|c|c|c|}
\hline \multirow{2}{*}{ CODIFICAÇÃO } & \multicolumn{3}{|c|}{ NÍVEIS AVALIADOS } \\
\hline & $\mathbf{A}$ & B & $\mathbf{C}$ \\
\hline FG & $\begin{array}{c}\text { Ambos avaliadores } \\
\text { possuem a mesma } \\
\text { graduação do curso } \\
\text { avaliado }\end{array}$ & $\begin{array}{l}\text { Um dos avaliadores } \\
\text { possui graduação no } \\
\text { curso avaliado e outro } \\
\text { possui graduação } \\
\text { diversa da do curso } \\
\text { avaliado }\end{array}$ & $\begin{array}{l}\text { Ambos avaliadores } \\
\text { possuem graduação } \\
\text { diversa daquela do } \\
\text { curso avaliado }\end{array}$ \\
\hline TM & $\begin{array}{c}\text { Ambos avaliadores são } \\
\text { doutores }\end{array}$ & $\begin{array}{c}\text { Somente um dos } \\
\text { avaliadores é doutor }\end{array}$ & $\begin{array}{l}\text { Ambos avaliadores não } \\
\text { são doutores }\end{array}$ \\
\hline MG & $\begin{array}{c}\text { Ambos avaliadores } \\
\text { pertencem a quadros de } \\
\text { IES Públicas }\end{array}$ & $\begin{array}{c}\text { Um dos avaliadores } \\
\text { pertence a quadro de } \\
\text { IES Pública e o outro } \\
\text { avaliador de IES } \\
\text { Privada }\end{array}$ & $\begin{array}{c}\text { Ambos avaliadores } \\
\text { pertencem a quadros de } \\
\text { IES Privadas }\end{array}$ \\
\hline OG & $\begin{array}{c}\text { Ambos avaliadores } \\
\text { advém da mesma } \\
\text { Região Geográfica do } \\
\text { Brasil }\end{array}$ & $\begin{array}{l}\text { Ambos avaliadores } \\
\text { advém de Regiões } \\
\text { Geográficas distintas }\end{array}$ & $=$ \\
\hline
\end{tabular}

Fonte: INEP (2018) 
A utilidade do sistema de avaliação só poderá ser validada após minuciosa análise de uma quantidade significativa de avaliações, entendendo por essa, avaliações feitas em todos os Estados brasileiros, em cursos de todas as áreas do conhecimento e por comissões de avaliação formadas por avaliadores das mais diferentes características. Uma das possibilidades é o emprego de metodologias e técnicas de análise de resultados. Existem diferentes abordagens para a análise de conteúdo as quais muitas vezes empregam conceitos e terminologias distintas em cada etapa. No presente trabalho, segue-se a metodologia conceituada por Bardin (2006, 2011), adaptada, na qual é empregada como uma técnica de análise de dados, que utiliza procedimentos sistemáticos e objetivos, sem deixar de lado a finalidade de inferir indicadores (quali ou quantitativos) aos dados analisados, ou seja, visa ultrapassar incertezas e enriquecer a leitura dos dados obtidos. Bardin (2006) organiza a análise em três fases: 1) pré-análise, 2) exploração do material e 3) tratamento dos resultados, inferência e interpretação.

No presente estudo, objetivou-se analisar a influência de diversos fatores sobre o resultado da avaliação emitida na Dimensão 1 (didático-pedagógica), pelos avaliadores do MEC, a partir de avaliações de autorização do curso de Administração (bacharelado, presencial).

Partindo-se de uma amostra obtida de um amplo banco de dados fez-se análise estatística almejando analisar a contribuição da avaliação in loco (nos moldes hoje estabelecidos pelo MEC) como indutoras (ou não) da qualidade nos cursos avaliados

\section{RESULTADOS E DISCUSSÕES}

No presente estudo, utilizou-se a amostra constituída conforme descrito no item 3.2, a qual foi submetida a tratamento estatístico empregando o programa Microsoft Excel, do Office XP. Para o tratamento dos dados, empregou-se, de acordo com a adequação de análise descritiva dos dados, com média aritmética, desvio padrão, erro padrão, mediana, modo, variância, além de montagem de histograma confrontando bloco e frequência, de modo a aferir a existência de associação entre as variáveis estudadas (FG, TM, MG e OG) e o Conceito Final da Dimensão $1(\mathrm{CF})$, atribuído pelos avaliadores. Foram efetuadas correlações bivariadas, sendo considerado nível de confiança de $95 \%$, ou seja, $\mathrm{p} \leq 0.05$.

A amostra é composta de 96 (noventa e seis) avaliações, nas quais foram conceituados, na Dimensão 1, os itens: Política Institucional para o Curso, Objetivo, Perfil do Egresso, Estrutura Curricular, Componentes Curriculares, Metodologia, Estágio Curricular Supervisionado, Atividades Complementares, TCC, Apoio Discente, Tecnologias de 
Gráfico 1 - Frequências do Valor Médio De Classes do Conceito Final (CF) atribuído a Dimensão 1.

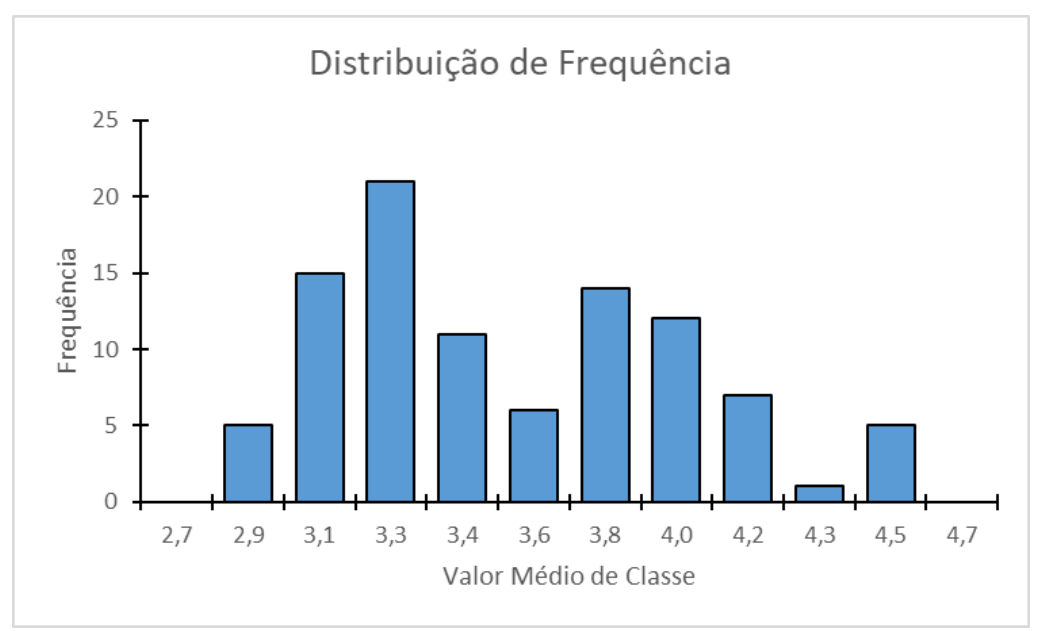

Fonte: Pesquisa de Campo, 2018.

Observando o Gráfico 1, tem-se a confirmação de que, embora todos os conceitos sejam passíveis de determinar qualidade satisfatória aos cursos avaliados, o mesmo não se pode dizer com relação a capacidade desses conceitos permitirem indução de qualidade aos cursos, vez que, avaliando-se sob condições controladas, a conceituação não poderia variar, ainda mais no volume de variação verificada. A insegurança provocada não permite credibilidade ao ponto de gerar indução de qualidade.

Como a discrepância encontrada e seu resultado danoso a geração de indução de qualidade, passou-se a analisar a influência de fatores não relacionados a construção dos itens que compõe a dimensão 1, mais especificamente as características dos avaliadores que compõem as Comissões de Avaliação da amostra, selecionando-se, para tanto, os fatores descritos no item 3.3: FG, TM, MG e OG.

A Quadro 3 apresenta uma análise feita nas características gerais das Comissões de Avaliadores que foram usadas nas 96 (noventa e seis) avaliações aqui trabalhadas, conforme tabela 1, exposta no item 3.3:

Quadro 3 - Características Gerais das Comissões de Avaliação

\begin{tabular}{|l|c|c|c|}
\hline \multirow{2}{*}{ CODIFICAÇÃO } & \multicolumn{3}{|c|}{ NÍVEIS AVALIADOS } \\
\cline { 2 - 4 } & A & B & C \\
\hline FG & 69 & 27 & 0 \\
\hline TM & 42 & 41 & 13 \\
\hline MG & 38 & 45 & 13 \\
\hline OG & 49 & 47 & $=$ \\
\hline
\end{tabular}

Fonte: Pesquisa de campo, 2018. 
Observando-se as características das Comissões de Avaliadores, nota-se uma tendência do INEP em designar avaliadores formados no curso avaliado, preferencialmente doutores e oriundos de instituições públicas, independentemente da região que se originam.

Isso se justifica, quando se vê que dos 192 (cento e noventa e dois) avaliadores envolvidos nas avalições da amostra, 165 (86\%) deles são graduados no curso avaliado (administração), 125 (65\%) deles são doutores, 121 (63\%) deles são oriundos de instituições públicas e há um equilíbrio total entre comissões cujos avaliadores originam-se da mesma região brasileira (51\%) e Comissões cujos avaliadores originam-se de regiões diversas do País $(49 \%)$.

A Tabela 1, por seu turno, relaciona e percentualiza os perfis trazidos na Tabela 3 aos grupos de conceitos aplicados ao indicador "Conceito Final da Dimensão 1":

Tabela 1 - Características das Comissões de Avaliação x Conceitos Aplicados

\begin{tabular}{|c|c|c|c|c|c|c|c|c|c|}
\hline $\begin{array}{c}\text { Conceitos } \\
\text { Globais } \\
\end{array}$ & $\begin{array}{c}\text { Níveis } \\
\text { Avaliados } \\
\end{array}$ & FG & $\%$ & TM & $\%$ & MG & $\%$ & OG & $\%$ \\
\hline \multirow{3}{*}{3} & $\mathrm{~A}$ & 36 & $78,3 \%$ & 18 & $39,1 \%$ & 20 & $43,5 \%$ & 21 & $45,7 \%$ \\
\hline & B & 10 & $21,7 \%$ & 21 & $45,7 \%$ & 20 & $43,5 \%$ & 25 & $54,3 \%$ \\
\hline & $\mathrm{C}$ & 0 & $0,0 \%$ & 7 & $15,2 \%$ & 6 & $13,0 \%$ & 0 & $0,0 \%$ \\
\hline \multirow{3}{*}{4} & A & 29 & $64,4 \%$ & 21 & $46,7 \%$ & 17 & $37,8 \%$ & 25 & $55,6 \%$ \\
\hline & $\mathrm{B}$ & 16 & $35,6 \%$ & 20 & $44,4 \%$ & 21 & $46,7 \%$ & 20 & $44,4 \%$ \\
\hline & $\mathrm{C}$ & 0 & $0,0 \%$ & 4 & $8,9 \%$ & 7 & $15,6 \%$ & 0 & $0,0 \%$ \\
\hline \multirow{3}{*}{5} & $\mathrm{~A}$ & 4 & $80,0 \%$ & 3 & $60,0 \%$ & 1 & $20,0 \%$ & 3 & $60,0 \%$ \\
\hline & B & 1 & $20,0 \%$ & 0 & $0,0 \%$ & 4 & $80,0 \%$ & 2 & $40,0 \%$ \\
\hline & $\mathrm{C}$ & 0 & $0,0 \%$ & 2 & $40,0 \%$ & 0 & $0,0 \%$ & 0 & $0,0 \%$ \\
\hline
\end{tabular}

Fonte: Pesquisa de campo, 2018.

Nesse cenário, percebe-se que, para cada grupo de conceito final aplicado a Dimensão 1, há um perfil de características de Comissão de Avaliadores predominante.

Ao analisar o grupo das 46 Comissões de Avaliadores que aplicaram o Conceito Final 3, para a Dimensão 1, vê-se que 36 (trinta e seis) delas (78,3\%) são formadas exclusivamente por avaliadores graduados no curso avaliado, 21 (vinte e uma) delas $(45,7 \%)$ são formadas exclusivamente por doutores, não há padrão predominante quanto a instituição de origem dos avaliadores, sendo que 20 (vinte) Comissões (43,5\%) são formadas por avaliadores que se original exclusivamente de IES pública e o mesmo número de 20 (vinte) Comissões $(43,5 \%)$ são mistas, compostas por 1 avaliador originário de instituição pública e o outro originário de instituição privada.

No que concerne a região de origem dos avaliadores, há uma pequena preponderância para Comissões compostas por avaliadores oriundos de regiões diferentes do País. Ao todo, são 25 (vinte e cinco) Comissões (54,3\%). Compilando, então, o perfil preponderante que aplica conceito 3 ao indicador Conceito Final da Dimensão 1 é constituído por Comissões composta 
por avaliadores graduados no curso avaliado, composta exclusivamente por doutores e oriundos de regiões diversas do País, não havendo um padrão preponderante quanto a organização administrativa da instituição de origem dos avaliadores.

Noutro giro, observando o grupo das 50 Comissões de Avaliadores que aplicaram o Conceito Final 4 e 5, para a Dimensão 1, vê-se que 33 (trinta e três) delas (66\%) são formadas exclusivamente por avaliadores graduados no curso avaliado, 24 (vinte e quatro) delas (48\%) são formadas exclusivamente por doutores, 25 (vinte e cinco) delas (50\%) são mistas, formadas por 1 avaliador oriundo de instituição pública e o outro de instituição privada e 28 (vinte e cinco) Comissões (56\%) são compostas por avaliadores oriundos da mesma região brasileira. Sintetizando, assim, o perfil preponderante que aplica conceitos 4 e 5 ao indicador Conceito Final da Dimensão 1 é constituído por Comissões composta por avaliadores graduados no curso avaliado, composta exclusivamente por doutores, oriundos um de instituição pública e o outro de instituição privada e vindos da mesma região brasileira.

\section{CONSIDERAÇÕES FINAIS}

Destarte, como foi possível identificar um padrão diverso de composição de Comissão preponderante para aplicação de conceito 3 (satisfatório) e conceitos 4 (muito bom/muito bem) e 5 (excelente), pode-se inferir que os conceitos aplicados não estão relacionados somente aos indicadores de qualidade propostos pelo MEC, a saber, a DCN do curso avaliado e os indicadores e descritores do IACG, mas sim, também, as características dos avaliadores que compõem as Comissões de Avaliação do INEP.

Considera-se, que mesmo os cursos de graduação, tratados por essa pesquisa, que obtém Diretrizes Curriculares Nacionais próprias, que ditam exatamente os princípios formativos do curso e a qualidade geral esperada na oferta, observa-se o grau de subjetividade com distanciamento considerável e uma variação em relação aos resultados finais das avaliações de cursos.

O grau de subjetividade esperado em avaliações externas, compromete-se ao verificar a intensidade desta subjetividade, quando os perfis dos avaliadores trazem ao processo avaliativo um resultado final do processo bastante diferenciado entre si, e que, por sua vez, pode comprometer a qualidade de melhoria cíclica ao curso avaliado, em função da insegurança gerada na aplicação dos conceitos. 


\section{REFERENCIAS}

ALMEIDA, Marcelo Cavalcanti. Auditoria: um curso moderno e completo. 4. ed. São Paulo: Saraiva, 1990.

AMARAL, Nelson Cardoso. Financiamento da educação superior: estado x mercado. São Paulo: Cortez; UNIMEP, 2003.

AUDIBRA- INSTITUTO DOS AUDITORES INTERNOS DO BRASIL. Normas brasileiras para o exercício da auditoria interna. 2.ed. São Paulo, 1991.

BARDIN, L. Análise de conteúdo. Tradução de L. de A. Rego \& A. Pinheiro. Lisboa: Edições 70, 2006.

BRASIL. Decreto $\mathbf{n}^{\mathbf{0}} . \mathbf{5 7 7 3}$, de 09 de maio de 2006. Dispõe sobre o exercício das funções de regulação, supervisão e avaliação de Instituições de educação e cursos superiores de graduação e sequenciais no sistema federal de ensino. Brasília, DF. 2006. Diário Oficial, Poder Executivo, Brasília, DF, 10 mai. 2006, n.88, p.6. Seção I.

BRASIL. Lei n. 10.269, de 29 de agosto de 2001. Dá nova denominação ao Instituto Nacional de Estudos e Pesquisas Educacionais - INEP. 2001. Diário Oficial, Poder Executivo, Brasília, DF, 30 ago. 2001, n.167, p.2. Seção I

BRASIL. Lei n. 378, de 13 de janeiro de 1937. Dá nova organização ao Ministério da educação e Saúde Pública. 1937. Disponível em <http://www2.camara.leg.br/legin/fed/lei/1930-1939/lei-378-13-janeiro-1937-398059publicacaooriginal-1-pl.html>. Consultado em 08/03/2017

BRASIL. Lei n. 378, de 13 de janeiro de 1937. Dá nova organização ao Ministério da educação e Saúde Pública. 1937. Disponível em <http://www2.camara.leg.br/legin/fed/lei/1930-1939/lei-378-13-janeiro-1937-398059publicacaooriginal-1-pl.html>. Consultado em 08/03/2017

BRASIL. Lei n. 9.394, de 20 de dezembro de 1996. Estabelece as Diretrizes e Bases da Educação Nacional. 1996. Disponível em <http://www.planalto.gov.br/ccivil_03/LEIS/19394.htm>.Consultado em 07/07/2018

COSTA, Camila F.; et al. Auditoria Interna das normas de qualidade para obtenção da ISO: um estudo de caso na indústria têxtil Dudalina S/A III Simpósio de Excelência em Gestão e Tecnologia, Resende - RJ, 2006. Disponível em: Acesso em: 06 de dezembro de 2010.

CREPALDI, Silvio Aparecido. Auditoria contábil: teoria e prática. São Paulo: Atlas, 2000.

FRANCO, Hilário; MARRA, Ernesto. Auditoria Contábil. 2a ed. São Paulo: Atlas, 1992.

INEP. Nota Técnica $\mathbf{n}^{\mathbf{0}} \mathbf{. 0 8}$, em conjunto com a DAES, de 04 de março de 2015. Consolidação do Instrumento de Avaliação de Cursos de Graduação do Sistema Nacional de Avaliação da Educação Superior (SINAES). Brasília, DF. 2015. Disponível em <http://download.inep.gov.br/educacao_superior/avaliacao_cursos_graduacao/legislacao_nor mas/2015/nota_tecnica_DAES-INEP_n008-2015.pdf>.Consultado em 08/03/2017. 
INEP. Portaria no $\mathbf{~ 1 0 2 7}^{\mathbf{0}}$ de 15 de maio de 2006. Dispõe sobre banco de avaliadores do Sistema Nacional de Avaliação da Educação Superior - SINAES, a Comissão Técnica de Acompanhamento da Avaliação - CTAA, e dá outras providências. Brasília, DF. 2006. Disponível em <http://portal.mec.gov.br/arquivos/pdf/portaria1027.pdf >. Consultado em 08/03/2017.

MEC. Instrução Normativa SERES n⿳ 1/2017. 2017. Disponível em < http://portal.mec.gov.br/index.php?option=com_docman\&view=download\&alias=60631instrucao-normativa-n01-23022017-autorizacao-direito-pdf\&category_slug=marco-2017pdf\&Itemid=30192>. Consultado em 08/03/2017.

MEC. Instrução Normativa SERES no 2/2014. 2014 Disponível em < http://portal.mec.gov.br/index.php?option=com_docman\&view=download\&alias=16069-in02-2014-seres-pdf\&category_slug=julho-2014-pdf\&Itemid=30192>. Consultado em $08 / 03 / 2017$.

MEC. Instrução Normativa SERES no 3/2014. 2014. Disponível em < http://portal.mec.gov.br/index.php?option=com_docman\&view=download\&alias=16070-in03-2014-seres-pdf\&category_slug=julho-2014-pdf\&Itemid=30192>. Consultado em 08/03/2017.

PINHO, Ruth Carvalho de Santana. Fundamentos da auditoria: auditoria contábil: outras aplicações de auditoria. São Paulo: Atlas, 2007. 